\title{
THE IMPORTANCE OF UBIQUITIN E3 LIGASES, SCF AND APC/C, IN HUMAN CANCERS
}

\author{
OVIDIU VASILE BOCHIS ${ }^{1}$, BOGDAN FETICA ${ }^{2}$, CATALIN VLAD ${ }^{3}$, \\ PATRICIU ACHIMAS-CADARIU ${ }^{3}$, ALEXANDRU IRIMIE ${ }^{3}$
}

\author{
${ }^{1}$ Department of Medical Oncology, "Prof. Dr. Ion Chiricuta" Institute of Oncology, \\ Iuliu Hatieganu University of Medicine and Pharmacy, Cluj-Napoca, Romania \\ ${ }^{2}$ Department of Pathology, "Prof. Dr. Ion Chiricuta" Institute of Oncology, Iuliu \\ Hatieganu University of Medicine and Pharmacy, Cluj-Napoca, Romania \\ ${ }^{3}$ Department of Surgery, "Prof. Dr. Ion Chiricuta" Institute of Oncology, Iuliu \\ Hatieganu University of Medicine and Pharmacy, Cluj-Napoca, Romania
}

\begin{abstract}
A normal evolution of the cell-cycle phases consists of multiple consecutive events, which makes it a highly complex process. Its preservation is regulated by Cyclin-Cdks (cyclin-dependent kinases) interactions and protein degradation, which is often controlled by the ubiquitin-mediated proteolysis.

The goal of this review is to emphasize the most important features of the regulation of the cell-cycle involved in cancerogenesis, by presenting the involvement of E3 ubiquitin ligases SCF (Skp1-Cul1-F-box protein) and APC/C (Anaphase-promoting complex/cyclosome) in human malignancies. Also, we discuss the importance of the ubiquitin proteasome pathway blockade in cancer treatment. We know that a better understanding of the regulatory biology of the cell cycle can lead to the development of new target therapies for cancer.
\end{abstract}

Keywords: cell cycle, ubiquitin, SCF, cancer.

\section{Introduction}

The progression of the cellular cycle in eukariots is controlled by the interaction of cyclines and kinasedependent cyclines (Cdks) [1]. The formation of an active heterodimer through the interaction of Cdks with cyclines is extremely necessary, because cyclines do not have their own catalytic activity, and Cdks are inactive without a cyclin partner $[2,3]$. The proteic level of cyclines varies within the phases of the cellular cycle. The type D cyclines activate Cdk4 and Cdk6 in order to regulate the events in the G1 phase [1]. Type E and A cyclines activate Cdk2 and Cdk1 with effects on the events of the S phase [1,4]. Type $\mathrm{A}$ and $\mathrm{B}$ cyclines activate $\mathrm{Cdk} 1$ with a direct and regulatory action of the events in the mitosis [5]. The cyclineE-Cdk2 is activated in the late G1 phase, so as to promote the

Manuscript received: 06.12.2014

Accepted: 16.01.2015

Address for correspondence: Bochis.Ovidiu@umfcluj.ro entry into the $\mathrm{S}$ phase and thereafter the DNA replication $[1,4]$. CyclinA-Cdk2 and cyclinA-Cdk1 are involved in the progression of the $\mathrm{S}$ phase and the $\mathrm{G} 2 / \mathrm{M}$ transition, while cyclinB-Cdk1 is activated in order to promote the entry into the mitosis [1]. The activity of Cyclin/Cdks complexes is negatively regulated by the Cdk inhibitors [2,5]. The Cdk inhibitors belong to 2 families: Ink4 and Cip/Kip (kinase inhibitor protein). The Ink family includes $\mathrm{p} 15, \mathrm{p} 16, \mathrm{p} 18$ and p20 [1,4]. The Cip/Kip family includes p21, p27 and p57 [6]. The Ink4 family inhibits the activity of Cdk 4 and Cdk6. The Cip/Kip family inhibits mainly the activity of Cdk2, binding to the CyclinE-Cdk2 and CyclinA-Cdk2 complexes [4]. P27 negatively regulates Cdk2-Cyclin $\mathrm{A} / \mathrm{E}$ and can positively regulate CyclinD-Cdk4 [7]. In normal conditions, the proliferation signals determinate the synthesis of cyclinD. CycD attaches to $\mathrm{Cdk} 4 / 6$ and initiates the phosphorilation (therefore the inactivation) of the retinoblastoma protein $(\mathrm{Rb})$, with the release of the 
transcriptional factor E2F $[8,9]$. This allows the activation and transcription of responsive E2F genes, which are necessary for the transition of G1/S (cyclinE) and initiation of DNA replication (cyclinA) [10,11]. Another function of CycD-Cdk4/6 is to maintain CycE-Cdk2 in an active form by a competitive coupling of the free p27. This blocks the formation of $\mathrm{p} 27 / \mathrm{CycE}-\mathrm{Cdk} 2$, which determines an additional release of E2F [12]. The high level of free E2F promotes the CycE synthesis in the middle and late G1phase and by this it facilitates the association of $\mathrm{CycE}$ with $\mathrm{Cdk} 2$, resulting in supplementary CycE-Cdk2 complexes. This results in a greater release of $\mathrm{E} 2 \mathrm{~F}$, which accomplishes a positive-feedback between E2F and CycE. High levels of E2F and CycE-Cdk2 allow the cells to cross the transition G1/S and determine the entry into the $S$ phase [11]. The degradation of $\mathrm{CycD}$ starts in the middle of the $\mathrm{G} 1$ phase, which allows the release of $\mathrm{p} 27$, bound to the $\mathrm{CycD}$ Cdk4/6 complex [8]. Moreover, p27 binds to CycE-Cdk2 and $\mathrm{CycA}-\mathrm{Cdk} 2$. Even if p27 can inhibit their activity, a high level of CycE-Cdk2 can initiate p27 degradation through a phosphorylation mechanism at the $\operatorname{Thr}^{187}$ [13]. Likewise, the accumulation of Skp2, a negative regulator of p27, starts in the late G1-phase, thanks to the decrease in activity of $\mathrm{APC} / \mathrm{C}^{\mathrm{Cdh} 1}$ [8]. Altogether, these events in the G1 phase determine a significant degradation of p27 at the end of it, which determines the intracellular accumulation of CycE-Cdk2 and therefore the progression of the cell cycle.

The resulting signals of the detection of DNA lesions induce the release of $\mathrm{p} 53$ by its inhibitor Mdm2, with the activation of p53 as a transcriptional factor for several genes involved in DNA-repairing and the cell cycle arrest $[9,14,15]$. Among these there is also the Cdk inhibitor p21, which negatively regulates $\mathrm{CycE}-\mathrm{Cdk} 2$ and $\mathrm{CycA}-\mathrm{Cdk} 2$ $[9,16]$. This leads to the decrease in E2F releasing, and thereby the decrease of the synthesis of $\mathrm{CycE}$ and $\mathrm{CycA}$, which finally results in blocking the progression of the cell cycle [16].

\section{Ubiquitin proteasomic system - a proteolytic machinery}

The proteic level of these regulators is controlled by the ubiquitin proteasomic system (UPS) [2,17]. The degradation mediated by this proteolytic-complex is an irreversible mechanism which ensures the unidirectional way of the cellular cycle [2].

UPS is composed of 3 types of enzymes: an ubiquitin-activating enzyme (E1), an ubiquitin-conjugating enzyme (E2) and an ubiquitin-ligase (E3). These enzymes compose a cascade of enzymatic reactions, which results in UPS functioning $[2,18]$. The first step is ATP-dependent and presumes the binding of ubiquitin to the E1. Ubiquitin, a 76 aminoacid- protein, after its activation, is subsequently transferred to the E2 enzyme $[18,19]$. Furthermore, ubiquitin, linked to E2, interacts with a specific partner, E3, and transfers the ubiquitin molecules on the proteic substrate leading to the formation of mono- and polyubiquitylations [6]. After this, the polyubiquitylated protein suffers proteic degradation by the $26 \mathrm{~S}$ proteasome in an ATP-dependent manner $[2,6]$. The human proteome contains two ubiquitin E1 enzymes, about 50 E2s and 600 E3s [20]. Generally, the specificity of the target-protein depends on E3, which is the reason why the disorder of E3-ligase often leads to cancerous growth $[9,18]$.

The ubiquitin ligases were divided in 3 main classes, based on specific structural reasons, namely: Cullin-based E3s [which contains SCF, APC/C and VBC (von Hippel Landau tumor suppressor/Elongin BC complex)], HECTbased E3s (which contains E6-AP), and RING-finger based E3s (which contains Mdm2 and Cbl) [14].

Two important types of E3 enzyme are considered to have a significant role in regulating the progression of the cell cycle: the anaphase-promoting complex or cyclosome (APC/C) and the SCF complex. SCF is active throughout the entire cellular cycle, and the activity of APC/C takes place between the metaphase and the end of the next G1phase [2]. APC/C is essential for separating the chromatinsisters in the anaphase and for the crossing of the cells from the $M$ phase to the G1. These events are mediated by the ubiquitylation of the inhibitors of the anaphase, known as securins (Pds1 or Cut2) [2,8]. The SCF complex mainly regulates the progression of G1 to S-phase [21]. Disorders of the proteolytic system can lead to cellular proliferation, genomic instability and cancer $[1,2,18]$.

\section{Skp1-Cullin1-F-box E3 ubiquitin-ligase}

The SCF complex consists of 4 components: 3 constant subunits Skp1, Rbx1 and Cullin1, and a variable subunit, the F-box-protein [2,6]. Cul 1 is the cornerstone on which the subunits Rbx1 and Skp1 are assembled. Rbx1 binds to E2 and Skp1 binds to the proteic subunit F-box [22,23]. Each F-box protein binds to a specific subset of substrate proteins, promoting their degradation [24]. To date, 70 types of F-box proteins have been identified $[18,21]$.

Each F-box protein has a protein-protein interaction domain, important for the attachment and recognition of the substrate [19]. There are 3 classes: WD40 repeatcontaining F-box proteins (FBXWs), such as $\beta$-TRCP and FBW7; leucine-rich repeats (LRRs)-containing F-box proteins (FBXLs), including Skp2 and F-box proteins containing other diverse domains (FBXOs), including other types of proteins with several types of domains in the terminal C-region $[17,25]$.

Skp2 is an F-box protein that recognizes the phosphorylated p27 in the p27/Cdk2-cyclinE complex [17]. The SCF ${ }^{\text {Skp2/Cks1 }}$ complex binds to $\mathrm{p} 27$ at two sites, one at the $\mathrm{Thr}^{187}$ level through Cks1, and the other at the Glu ${ }^{185}$ level through the interface offered by the Skp2/Cks1 complex [7]. In the absence of p27, Cdk2-cyclin E and Cks1 raise the 
phosphorylation of Skp2. This phosphorylation determines the auto-ubiquitination and subsequent degradation of Skp2 [7]. The over-expression of Skp2 or the expression in several phases when it should be low (for example in the G1-phase) gives an advantage to the cellular growth due to p27 degradation [19].

$\boldsymbol{\beta}$-TrCP has a dual role in controlling the activity of Cdk1. In the S-phase and the mitosis, $\beta$-TrCP decreases the activity of Cdk1 by inducing Cdc25A and EMI1 degradation [19]. Meanwhile, it raises its activity in G2-M phase by inducing claspin and WEE1 degradation. It also stabilizes EMI1, an inhibitor of APC/C [21]. For these reasons it is considered that $\beta$ - $\operatorname{TrCP}$ possess both oncogenic and tumor suppressive characteristics [19].

FBW7 works as a tumor suppressor [2]. Its role as an oncosupressor protein is outlined by the analysis of its substrates, which work as cell-cycle activators with oncogenic properties: cyclin E, Notch1, Notch4, presenilin, c-Myc and c-Jun $[2,21]$. The genetic inactivation of $\mathrm{Fbw} 7$ in cancer cells offers a characteristic phenotype distinguished by the presence of micronuclei and chromosomal instability [21].

\section{$\mathrm{APC} / \mathrm{C}$ is a multifunctional $\mathrm{E} 3$ ligase}

$\mathrm{APC} / \mathrm{C}$ regulates important cellular events, including mitotic progression, DNA replication, cellular differentiation, genomic integrity and signaling transduction [1]. Pathological and epigenetic studies demonstrate that the dysfunction of certain APC/C components, such as APC6, APC 8 and Cdh1 or Cdc20, correlates to certain types of cancer, including colorectal cancer [26], B-cell lymphoma, gastric and lung cancer $[27,28]$. The activation of $\mathrm{APC} / \mathrm{C}$ is dependent on co-activator proteins WD40: Cdc20 and Cdh1 $[1,8]$. APC/ $\mathrm{C}^{\mathrm{Cd} 220}$ initiates the anaphase and leads the exit of the mitosis by inactivating $\mathrm{Cdk} 1$, while $\mathrm{APC} / \mathrm{C}^{\mathrm{Cdh} 1}$ ensures a stable G1-phase maintaining a low activity of Cdk [2,29]. The statement that $\mathrm{APC} / \mathrm{C}$ is involved in cancerogenesis is sustained by the fact that certain substrates such as Aurora-A, Skp2, Cdc25A, Cdc25B, Cyclin A and Cyclin $B$ are frequently over-expressed in different types of cancer [1]. The Cdc25A phosphatase promotes the entrance into the S-phase and the mitosis by dephosphorylation and activation of Cdk1/ 2 [1,8]. Aurora A and B are important mitotic-kinases, and are involved in the maturation of the centrosome and the separation of the chromosome $[1,8]$. The APC/C complex regulates the expression of these substrates according to the cell cycle phases [8]. Moreover, inactivatory mutations of APC4, APC6/Cdc16 and APC8/ $\mathrm{Cdc} 23$ have been discovered in colon cancer cells $[1,30]$. The high expression of APC/C inhibitors is as well frequently observed in cancer, including Mad2, BubR1, Bub1 and Emi1 [1]. Emi 1 inhibits Cdc20 and Cdh1 in Sand G2-phases, thus promoting the entrance in the S-phase and the mitosis [29,31].

Certain studies have showed that DNA lesion can lead to an activation of $\mathrm{APC} / \mathrm{C}^{\mathrm{Cdh} 1}$, causing cell-cycle arrest in the G1 phase by decreasing the activity of cyclin-Cdk [32]. DNA-lesion in the G1 phase activates p53, which inactivates Cdk2 through p21 activity [29].

\section{E3-ligase interaction regulates cell-cycle}

The interaction between SCF and $\mathrm{APC} / \mathrm{C}$ in leading the development of the cell cycle is at best reflected in the regulation of the cellular level of Skp2 by APC/C [7,33]. mRNA Skp2 is present throughout the cellular cycle, with minor fluctuations [34]. Skp2 protein, on the other hand, is absent in G0 and G1, it accumulates in the G1-S transition and persists throughout the S-phase to the mitosis [30]. The discrepancy between the proteic level from G0/G1 and the S-phase is due to the differentiation in the protein stability $[30,35]$. Skp2 is highly unstable in G0/G1, but after its entry in the S-phase its stability grows significantly $[30,35]$. The mechanism which controls Skp2 expression and protein stability is not completely understood, there being several known regulators (see Tab. I). In addition, some studies prove that Skp2 degradation in G0/G1 is mediated by APC/ $\mathrm{C}^{\mathrm{Cdh} 1}$ ubiquitin ligase $[30,33]$. It has been noticed that the over-expression of $\mathrm{Cdh} 1$ in the cells leads to a considerable destabilization of Skp2 [30]. Some control mechanisms ensure the activity of $\mathrm{APC} / \mathrm{C}^{\mathrm{Cdh} 1}$ only in the late $\mathrm{M}$ phases and G0/G1 [7,33]. The complex is activated by binding dephosphorylated Cdh1 to APC/C in the late M phase [7]. The absence of activity of Cdk 1 and $\mathrm{Cdk} 2$ kinases preserves $\mathrm{APC} / \mathrm{C}^{\mathrm{Cdh} 1}$ and keeps it functional throughout $\mathrm{G} 1$ and G0. At the G1-S transition, the functioning of APC/ $\mathrm{C}^{\mathrm{Cdh} 1}$ is blocked by the interaction of Cdh1 with the inhibitory protein Emi1, as well as by the Cdh1- phosphorylation Cdk-mediated [29]. The inactivation of $\mathrm{APC} / \mathrm{C}^{\mathrm{Cdh} 1}$ allows the accumulation of Skp2 and Cks1, forming an active $\mathrm{SCF}^{\text {Skp2-Cks1 }}$, which prepares p21 and p27 for the ubiquitinmediated degradation. The over-expression of Skp2 in different types of cancer can be a consequence of $\mathrm{Cdh} 1$ inactivation or low-expression [30].

Table I. Upstream regulators of Skp2.

\begin{tabular}{lccc}
\hline Pathway & Regulation & Cancer type & References \\
\hline PI3K/Akt & Up-regulates & colon/prostate/breast & $36,37 / 18 / 38$ \\
\hline PTEN & Down-regulates & colon/prostate & $39,40 / 38$ \\
\hline APC/C Cdh1 & Down-regulates & colon & 1,27 \\
\hline RECK & Down-regulates & colon & 41,42 \\
\hline Androgen & Up-regulates & prostate & 18,43 \\
\hline mTOR & Up-regulates & breast & 38,44 \\
\hline
\end{tabular}

Retinoblastoma protein regulates the transcription of Skp2 gene and the proteic stability of Skp2, functioning as a scaffold between Skp2 and its ubiquitin ligase, APC/ $\mathrm{C}^{\mathrm{Cdh} 1}$ [45]. This mediation of the interaction, which is facilitated by $\mathrm{Rb}$, determines Skp2 degradation and contributes to its post-transcriptional regulation [46]. In the early G0 and G1-phase, a part of the Rb molecules 
can suppress the expression of Skp2, keeping the contact of Skp2 with $\mathrm{APC} / \mathrm{C}^{\mathrm{Cdh} 1}$. Other $\mathrm{Rb}$ molecules sequester the E2F activator, which prevents genetic transcription of Skp2 [46]. Both mechanisms maintain a low level of Skp2 and determine p27 stability, and inhibit cyclin E-Cdk2, $\mathrm{Rb}$ phosphorylation and $\mathrm{E} 2 \mathrm{~F}$ release [46]. In the late $\mathrm{G} 1$ phase the $\mathrm{Rb}$ phosphorylation starts with the E2F release, which determines the induction of Skp2 gene $[9,46]$. The contact between $\mathrm{APC} / \mathrm{C}^{\mathrm{Cdh} 1}$ and $\mathrm{Skp} 2$ is as well lost with the decrease of the degradation's efficacy. Moreover, the E2F-dependent induction of Emil inhibits the $\mathrm{APC} / \mathrm{C}^{\mathrm{Cdh} 1}$ activity [47]. These data suggest that Skp2 over-expression in cancer can be a consequence of $\mathrm{Rb}$ pathway disorder, which is frequently seen in cancer [46].

In order to outline the involvement of $\mathrm{APC} / \mathrm{C}^{\mathrm{Cdh} 1}$ in cancerogenesis by degradation of Skp2, the axis of APC/ $\mathrm{C}^{\mathrm{Cdh} 1}$-Skp2-p27 involved in colorectal cancerogenesis was analyzed. The percentage of $\mathrm{Cdh} 1$ and p27 positive samples in tumoral tissue was significantly lower compared to adjacent normal tissue [27]. In reverse, the percentage of Skp2-positive samples in tumoral tissue was significantly higher compared to normal tissue [27]. High expression of Cdh1 in colon cancer cells was associated with a low tumoral histological degree. Moreover, the depletion of Cdh1 trough RNA interference in colon cells determines a growth of cellular proliferation, with a significant raise in numbers of the cells in the S-phase [27]. Over-expression of Cdh1 in colon cancer cells determines the reduction of Skp2 with a significant raise in p27, decreasing the cell growth and cancerous cell numbers in the S-phase [27].

\section{The $26 \mathrm{~S}$ proteasome - a key role in proteolytic degradation}

The proteasome is a multiproteic cellular complex, discovered by Hershko, Ciechanover and Rose - distinguished with the Nobel Prize for Chemistry in 2004 [48]. The proteasome directly or indirectly regulates several important cellular processes: proliferation, apoptosis, angiogenesis and metastasis [49]. The $26 \mathrm{~S}$ proteasome is a non-lisosomal proteolitic complex, found as well in the cytoplasm as in the nuclei of eukariots, and plays a crucial role in normal cellular functioning [50]. The $26 \mathrm{~S}$ proteasomic complex is involved in p27 degradation, therefore promoting cell cycle progression with effects on the cellular proliferation, uncontrolled cellular growth and cancerous cells development $[48,50]$. Cyclines are as well regulated by the $26 \mathrm{~S}$ proteasome, their degradation is possible after a prior ubiquitination of the APC/C complex [51]. Therefore, the proteasome has become an attractive target for anti-cancer treatments. Some proteasome inhibitors which act on proteolytically-active sites of the $26 \mathrm{~S}$ proteasomic complex have demonstrated anti-tumor effects by inducing apoptosis in different tumor types [50]. Moreover, proteasomic inhibitors induce cell cycle arrest, inhibit angiogenesis, cellular adhesion and migration, immune and inflammatory response and the reparatory response of the DNA [50]. Proteasomic inhibitors raise the level of p27 and p21, inhibiting Cdks with an effect on cellular growth and cell cycle course [48]. The antitumor effects of proteasomic inhibitors have been noticed in several cancer cell lines and animal-cancer models, including: lymphomas, leukemias, melanomas, pancreatic, prostate, breast or colon cancer [50,52]. These studies have shown that cancerous cells are much more sensitive to proteasomic inhibitors and that complete blocking of proteasome is not necessary to obtain anti-tumoral effect [50]. That is why the inhibition of proteasome has become an attractive target for treating cancer. The proteasomic inhibitors have a large spectrum of antiproliferative and proapoptotic effects, but with a low potency [50,52]. Among the inhibitors, Bortezomib (Velcade) is the distinguished one, and is used in treating multiple myeloma and mantlecell lymphoma. Bortezomib binds to the catalytic core subunit of the proteasome [53]. Several clinical studies have established Bortezomibs effects in non-small cell lung cancer, pancreatic and prostate cancer $[54,55,56]$. There are various proteasomic inhibitors, with great potential, analyzed in some clinical trials, such as: carfilzomib, ONX0912, marizomib, CEP-18770 and MLN9708 [8]. Carfilzomib has a great selectivity for $26 \mathrm{~S}$ proteasome and a better tolerability than Bortezomib, in vitro as well as in vivo. Carfilzomib was FDA- approved for treating patients with relapses and refractory multiple myeloma, proving its high potency and its better therapeutic index [8].

\section{Conclusions and perspectives}

Therapy directed towards individual components of E3-ligases or ligase-families known to be involved in human cancers could be more efficient than proteasomic inhibitors. The inhibiton of a single E3-ligase could be the best therapeutic approach, taking into account that it would affect only a limited number of proteins, and would have a better therapeutic response, with less adverse effects [8]. Regarding the SCF complexes- inhibiting F-box-substrate interaction or F-box- SCF binding, these are attractive therapeutic targets. The inhibitory molecule CpdA prevents Skp2 binding to the SCF ligase complex, inducing G1/S arrest and apoptosis, consequently stabilizing p27 and p21. Much more, CpdA sensitizes multiple myeloma cells to cytostatic agents and Bortezomib, being active as well on lymphoblasts and myeloid leukemia blasts [57]. There are many E3-ligase inhibitors in clinical trials, against Mdm2, Plk1, Met30, with promising results [8]. Their pharmacological modulation might offer specific therapies in a variety of cancers. The success depends on the pharmacological progress, on developing potent inhibitors of the F-box protein and furthermore, on the better understanding of implied mechanisms. 


\section{Acknowledgments}

This paper was published under the framework of the European Social Found, Human Resources Development Operational Programme 2007-2013, project no. POSDRU/159/1.5/S/138776.

\section{References:}

1. Kudo Y, Tsunematsu T, Takata T. Deregulation of Anaphasepromoting Complex/cyclosome-dependent Proteolysis in Cancer. Journal of Oral Biosciences. 2010;52(4):388-401.

2. Nakayama KI, Nakayama K. Ubiquitin ligases: cell-cycle control and cancer. Nat Rev Cancer. 2006;6(5):369-381.

3. Morgan DO. Principles of CDK regulation. Nature. 1995;374(6518):131-134.

4. Kotoshiba S, Gopinathan L, Pfeiffenberger E, Rahim A, Vardy LA, Nakayama K, et al. p27 is regulated independently of Skp2 in the absence of Cdk2. Biochim Biophys Acta. 2014;1843(2):436445.

5. Sherr CJ. Mammalian G1 cyclins. Cell. 1993;73(6):1059-1065. 6. Hershko DD. Oncogenic properties and prognostic implications of the ubiquitin ligase Skp2 in cancer. Cancer. 2008;112(7):14151424.

7. Xu S, Abbasian M, Patel P, Jensen-Pergakes K, Lombardo CR, Cathers BE, et al. Substrate recognition and ubiquitination of SCFSkp2/Cks1 ubiquitin-protein isopeptide ligase. J Biol Chem. 2007;282(21):15462-15470.

8. Bassermann F, Eichner R, Pagano M. The ubiquitin proteasome system - implications for cell cycle control and the targeted treatment of cancer. Biochim Biophys Acta. 2014;1843(1):150162.

9. Kitagawa K, Kotake Y, Kitagawa M. Ubiquitin-mediated control of oncogene and tumor suppressor gene products. Cancer Sci. 2009;100(8):1374-1381.

10. Dyson N. The regulation of E2F by pRB-family proteins. Genes Dev. 1998;12(15):2245-2262.

11. Satyanarayana A, Kaldis P. Mammalian cell-cycle regulation: several Cdks, numerous cyclins and diverse compensatory mechanisms. Oncogene. 2009;28(33):2925-3299.

12. Obaya AJ, Sedivy JM. Regulation of cyclin-Cdk activity in mammalian cells. Cell Mol Life Sci. 2002;59(1):126-142.

13. Coqueret $\mathrm{O}$. New roles for $\mathrm{p} 21$ and $\mathrm{p} 27$ cell-cycle inhibitors: a function for each cell compartment? Trends Cell Biol. 2003;13(2):65-70.

14. Nalepa G, Harper JW. Therapeutic anti-cancer targets upstream of the proteasome. Cancer Treat Rev. 2003;29:49-57.

15. Ciliberto A, Novak B, Tyson JJ. Steady states and oscillations in the p53/Mdm2 network. Cell Cycle. 2005;4(3):488-493.

16. Ling H, Samarasinghe S, Kulasiri D. Computational experiments reveal the efficacy of targeting CDK2 and CKIs for significantly lowering cellular senescence bar for potential cancer treatment. Biosystems. 2013;111(2):71-82.

17. Wang G, Chan CH, Gao Y, Lin HK. Novel roles of Skp2 E3 ligase in cellular senescence, cancer progression, and metastasis. Chin J Cancer. 2012;31(4):169-177.

18. Wang Z, Gao D, Fukushima H, Inuzuka H, Liu P, Wan L, et al. Skp2: A novel potential therapeutic target for prostate cancer. Biochim Biophys Acta. 2012;1825(1):11-17.

19. Frescas D, Pagano M. Deregulated proteolysis by the F-box proteins SKP2 and beta-TrCP: tipping the scales of cancer. Nat Rev Cancer. 2008;8(6):438-449.
20. Bhoj VG, Chen ZJ. Ubiquitylation in innate and adaptive immunity. Nature. 2009;458(7237):430-437.

21. Nakayama KI, Nakayama K. Regulation of the cell cycle by SCF-type ubiquitin ligases. Semin Cell Dev Biol. 2005;16(3):323333.

22. Hao B, Zheng N, Schulman BA, Wu G, Miller JJ, Pagano $\mathrm{M}$, et al. Structural basis of the Cks1-dependent recognition of p27(Kip1) by the SCFSkp2 ubipuitin ligase. Mol Cell. 2005;20(1):9-19.

23. Ungermannova D, Gao YF, Liu XD. Ubiquitination of p27(Kip1) requires physical interaction with cyclin $E$ and probable phosphate recognition by SKP2. J Biol Chem. 2005;280(34):30301-30309.

24. Shapira M, Ben-Izhak O, Bishara B, Futerman B, Minkov I, Krausz MM, et al. Alterations in the expression of the cell cycle regulatory protein cyclin kinase subunit 1 in colorectal carcinoma - Relation to p27(Kip1) and its ubiquitin ligase subunit, S phase kinase protein 2. Cancer. 2004;100(8):1615-1621.

25. Jin J, Cardozo T, Lovering RC, Elledge SJ, Pagano M, Harper JW. Systematic analysis and nomenclature of mammalian F-box proteins. Genes Dev. 2004;18(21):2573-2580.

26. Wang Q, Moyret-Lalle C, Couzon F, Surbiguet-Clippe C, Saurin JC, Lorca T, et al. Alterations of anaphase-promoting complex genes in human colon cancer cells. Oncogene. 2003;22(10):1486-1490.

27. Fujita T, Liu WJ, Doihara H, Wan Y. Regulation of Skp2-p27 axis by the Cdh1/anaphase-promoting complex pathway in colorectal tumorigenesis. Am J Pathol. 2008;173(1):217-228.

28. Singhal S, Amin KM, Kruklitis R, DeLong P, Friscia ME, Litzky LA, et al. Alterations in cell cycle genes in early stage lung adenocarcinoma identified by expression profiling. Cancer Biol Ther. 2003;2(3):291-298.

30. Bashir T, Pagano M. Don't skip the G(1) phase how APC/CCdh1 keeps SCFSkp2 in check. Cell Cycle. 2004;3(7):850-852.

29. van Leuken R, Clijsters L, Wolthuis R. To cell cycle, swing the APC/C. Biochim Biophys Acta. 2008;1786(1):49-59.

31. Reimann JD, Gardner BE, Margottin-Goguet F, Jackson PK. Emil regulates the anaphase-promoting complex by a different mechanism than Mad2 proteins. Genes Dev. 2001;15(24):32783285 .

32. Sudo T, Ota Y, Kotani S, Nakao M, Takami Y, Takeda S, et al. Activation of Cdh1-dependent APC is required for G1 cell cycle arrest and DNA damage-induced G2 checkpoint in vertebrate cells. EMBO J. 2001;20(22):6499-6508.

33. Bashir T, Dorrello NV, Amador V, Guardavaccaro D, Pagano M. Control of the SCF(Skp2-Cks1) ubiquitin ligase by the APC/ C(Cdh1) ubiquitin ligase. Nature. 2004;428(6979):190-193.

34. Wirbelauer C, Sutterlüty H, Blondel M, Gstaiger M, Peter $\mathrm{M}$, Reymond F, et al. The F-box protein Skp2 is a ubiquitylation target of a Cul1-based core ubiquitin ligase complex: evidence for a role of Cul1 in the suppression of Skp2 expression in quiescent fibroblasts. EMBO J. 2000;19(20):5362-5375.

35. Wei W, Ayad NG, Wan Y, Zhang GJ, Kirschner MW, Kaelin WG. Degradation of the SCF component Skp2 in cellcycle phase G1 by the anaphase-promoting complex. Nature. 2004;428(6979):194-198.

36. Chan C-H, Lee S-W, Wang J, Lin H-K. Regulation of Skp2 expression and activity and its role in cancer progression. ScientificWorldJournal. 2010;10:1001-1015.

37. Wang Z, Inuzuka H, Zhong J, Liu P, Sarkar FH, Sun Y, et al. Identification of acetylation-dependent regulatory mechanisms 
that govern the oncogenic functions of Skp2. Oncotarget. 2012;3(11):1294-1300.

38. Wang Z, Fukushima H, Inuzuka H, Wan L, Liu P, Gao D, et al. Skp2 is a promising therapeutic target in breast cancer. Front Oncol. 2012;1(57).

39. Hsu CP, Kao TY, Chang WL, Nieh S, Wang HL, Chung YC. Clinical significance of tumor suppressor PTEN in colorectal carcinoma. Eur J Surg Oncol. 2011;37(2):140-147.

40. Sawai H, Yasuda A, Ochi N, Ma J, Matsuo Y, Wakasugi T, et al. Loss of PTEN expression is associated with colorectal cancer liver metastasis and poor patient survival. BMC Gastroenterol. 2008;8:56.

41. Yoshida Y, Ninomiya K, Hamada H, Noda M. Involvement of the SKP2-p27(KIP1) pathway in suppression of cancer cell proliferation by RECK. Oncogene. 2012;31(37):4128-4138.

42. Noda M, Takahashi C. Recklessness as a hallmark of aggressive cancer. Cancer Sci. 2007;98(11):1659-1665.

43. Pernicová Z, Slabáková E, Kharaishvili G, Bouchal J, Král M, Kunická Z, et al. Androgen depletion induces senescence in prostate cancer cells through down-regulation of Skp2. Neoplasia. 2011;13(6):526-536.

44. Shapira M, Kakiashvili E, Rosenberg T, Hershko DD. The mTOR inhibitor rapamycin down-regulates the expression of the ubiquitin ligase subunit Skp2 in breast cancer cells. Breast Cancer Res. 2006;8(4):R46.

45. Binne UK, Classon MK, Dick FA, Wei W, Rape M, Kaelin WG, Jr., et al. Retinoblastoma protein and anaphase-promoting complex physically interact and functionally cooperate during cell-cycle exit. Nat Cell Biol. 2007;9(2):225-232.

46. Assoian RK, Yung Y. A reciprocal relationship between $\mathrm{Rb}$ and Skp2 - Implications for restriction point control, signal transduction to the cell cycle and cancer. Cell Cycle. 2008;7(1):2427.

47. Hsu JY, Reimann JD, Sørensen CS, Lukas J, Jackson PK.
E2F-dependent accumulation of hEmil regulates $\mathrm{S}$ phase entry by inhibiting APC(Cdh1). Nat Cell Biol. 2002;4(5):358-366.

48. Voutsadakis IA. The ubiquitin-proteasome system in colorectal cancer. Biochim Biophys Acta. 2008;1782(12):800-808.

49. Wolf DH, Hilt W. The proteasome: a proteolytic nanomachine of cell regulation and waste disposal. Biochim Biophys Acta. 2004;1695(1-3):19-31.

50. Frankland-Searby S, Bhaumik SR. The $26 \mathrm{~S}$ proteasome complex: An attractive target for cancer therapy. Biochim Biophys Acta. 2012;1825(1):64-76.

51. Keyomarsi K, Pardee AB. Redundant cyclin overexpression and gene amplification in breast cancer cells. Proc Natl Acad Sci U S A. 1993;90(3):1112-1116.

52. Uddin S, Ahmed M, Bavi P, El-Sayed R, Al-Sanea N, Abduljabbar A, et al. Bortezornib (Velcade) induces p27Kip1 expression through S-phase kinase protein 2 degradation in colorectal cancer. Cancer Res. 2008;68(9):3379-3388.

53. Adams J, Behnke M, Chen S, Cruickshank AA, Dick LR, Grenier L, et al. Potent and selective inhibitors of the proteasome: dipeptidyl boronic acids. Bioorg Med Chem Lett. 1998;8(4):333338.

54. Aghajanian C, Soignet S, Dizon DS, Pien CS, Adams J, Elliott PJ, et al. A phase I trial of the novel proteasome inhibitor PS341 in advanced solid tumor malignancies. Clin Cancer Res. 2002;8(8):2505-2511.

55. Scagliotti G. Proteasome inhibitors in lung cancer. Crit Rev Oncol Hematol. 2006;58(3):177-189.

56. Papandreou CN, Logothetis CJ. Bortezomib as a potential treatment for prostate cancer. Cancer Res. 2004;64(15):50365043.

57. Chen Q, Xie W, Kuhn DJ, Voorhees PM, Lopez-Girona A, Mendy D, et al. Targeting the p27 E3 ligase SCF $(\operatorname{Skp} 2=$ results in p27-and Skp2-mediated cell-cycle arrest and activation of autophagy. Blood. 2008;111(9):4690-9. 